\title{
Primary sclerosing cholangitis associated with severe ulcerative colitis in a young man
}

José Cândido Caldeira Xavier Júniora Kunie labuki Rabello Coelhoa ${ }^{a}$,igia Yukie Sassaki ${ }^{b}$, Fabio da Silva Yamashiro ${ }^{b}$, Kelly Cristhian Lima Oliveira ${ }^{b}$, Maria Aparecida Marchesan Rodrigues ${ }^{a}$

Xavier JCC Jr, Coelho KIR, Sassaki LY, Yamashiro FS, Oliveira KCL, Rodrigues MAM. Primary sclerosing cholangitis associated with severe ulcerative colitis in a young man. Autopsy Case Rep [Internet]. 2013; 3(4): 37-41. http://dx.doi. org/10.4322/acr.2013.037

\section{ABSTRACT}

Primary sclerosing cholangitis, a chronic progressive cholestatic liver disease, is the most serious hepatobiliary complication of ulcerative colitis (UC). The authors present the case of a severe and intractable form of UC associated with primary sclerosing cholangitis, in which the diagnosis of this hepatobiliary complication was made during the postmortem examination. A 19-year-old man, with an 8-month diagnosis of UC, was non-responsive to any therapeutic approach. He presented at the emergency care unit severely ill and with cachexia, and subsequently died of septic shock. The postmortem examination confirmed the clinical diagnosis of severe UC and disclosed the presence of primary sclerosing cholangitis. Although laboratory tests have shown a typical cholestatic profile with elevated alkaline phosphatase and gamma-glutamyl transferase levels, hepatic dysfunction was related to sepsis. This report highlights how challenging the diagnosis of primary sclerosing cholangitis can be and shows the value of the postmortem examination to add important information to a medical diagnosis.

Keywords: Cholangitis, Sclerosing; Colitis, Ulcerative; Autopsy.

\section{CASE REPORT}

A 19-year-old man presented at the emergency care unit complaining of lower abdominal pain, cramps, and bloody mucus diarrhea for several weeks. He had a previous history of chronic diarrhea and a confirmed diagnosis of ulcerative colitis (UC) (Figure 1A) 8 months earlier. At that time, he had pancolitis, which initially improved with oral mesalazine. However, the diarrhea relapsed and treatment with prednisone was carried out. As the outcome remained unfavorable, corticotherapy was replaced by azathioprine. The physical examination on admission disclosed a severely ill patient who was pale and dehydrated. $\mathrm{He}$ had a tender, distended abdomen with a positive rebound test, and cutaneous lesions of pyoderma gangrenosum, which was later confirmed by a skin biopsy. Abdominal plain radiography and computed tomography revealed ascites and colonic wall edema, not fulfilling the criteria for toxic megacolon. The results of the laboratory tests on admission are summarized in Table 1.

Liver function tests showed increased levels of alkaline phosphatase and gamma-

\footnotetext{
a Department of Pathology - Faculdade de Medicina - Universidade Estadual Paulista, Botucatu/SP, Brazil.

${ }^{b}$ Department of Internal Medicine - Faculdade de Medicina - Universidade Estadual Paulista, Botucatu/SP, Brazil.
}

Copyright $\odot 2013$ Autopsy and Case Reports - This is an Open Access article distributed of terms of the Creative Commons Attribution NonCommercial License (http://creativecommons.org/licenses/by/3.0/) which permits unrestricted non-commercial use, distribution, and reproduction in any medium provided article is properly cited. 

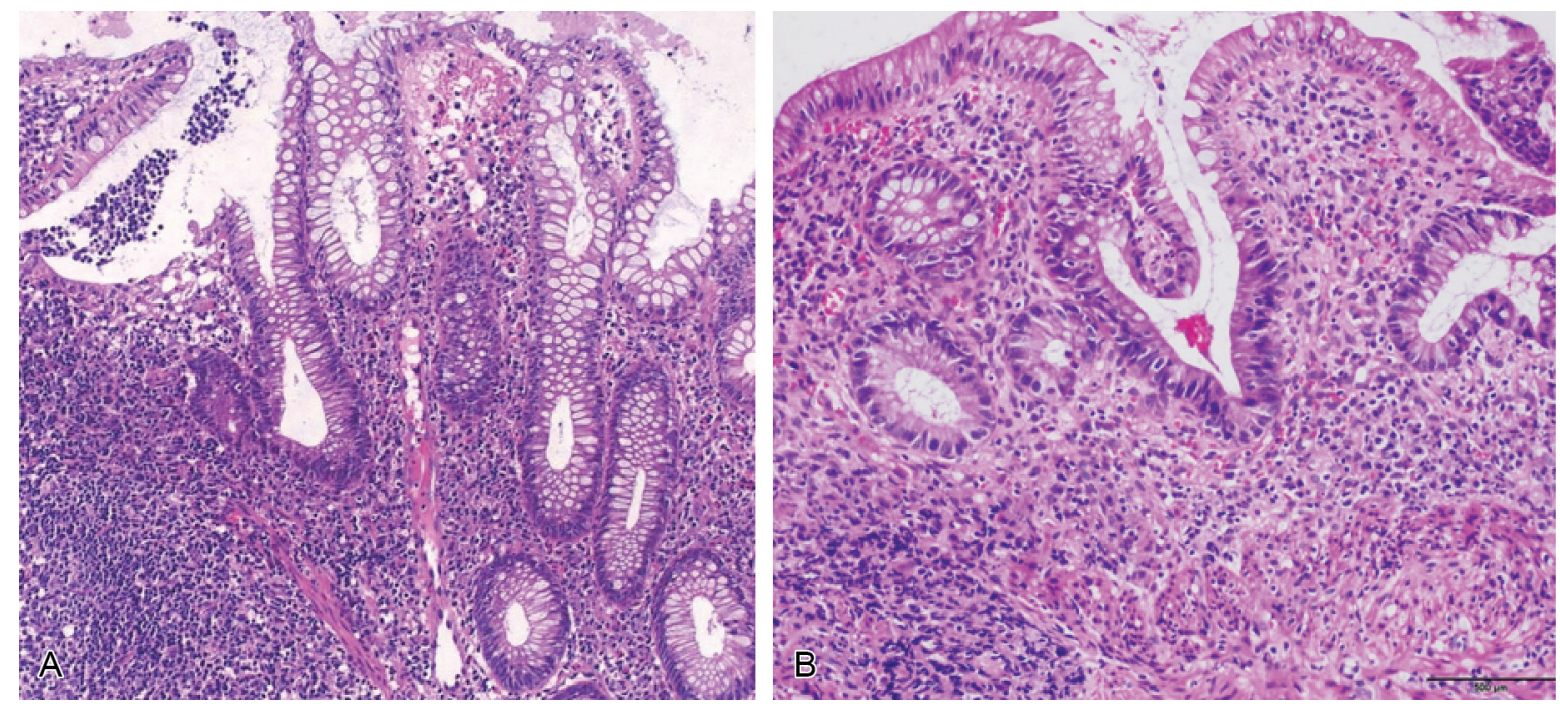

Figure 1 - Photomicrography of the intestinal mucosa showing pathologic features of ulcerative colitis (UC). A - Severe chronic active colitis (HE, 200X); B - Rectal mucosa showing atrophy, crypt distortion, and an infiltrate of lymphocytes and plasma cells (HE, 400X).

Table 1 - Initial laboratory workup

\begin{tabular}{cccccc}
\hline Exam & Results & RV & Exam & Results & RV \\
\hline Hemoglobin & 6.1 & $14-18 \mathrm{~g} / \mathrm{dL}$ & Urea & 50.0 & $19-42 \mathrm{mg} / \mathrm{dL}$ \\
Hematocrit & 18.8 & $40-57 \%$ & Creatinine & 2.7 & $0.8-1.5 \mathrm{mg} / \mathrm{dL}$ \\
Leucocytes & 35.5 & $4-11 \times 10^{3} / \mathrm{mm}^{3}$ & Potassium & 7.8 & $3.5-5.0 \mathrm{mEq} / \mathrm{L}$ \\
Bands & 5.0 & $1-5 \%$ & Sodium & 151 & $137-145 \mathrm{mEq} / \mathrm{L}$ \\
Segmented & 63.0 & $45-70 \%$ & ALT & 125 & $9-36 \mathrm{U} / \mathrm{L}$ \\
Eosinophilis & 1.0 & $1-4 \%$ & AST & 81 & $10-31 \mathrm{U} / \mathrm{L}$ \\
Basophilis & 1.0 & $0-2.5 \%$ & ALP & 188.0 & $10-100 \mathrm{U} / \mathrm{L}$ \\
Lymphocytes & 24.0 & $18-40 \%$ & yGT & 538.0 & $2-30 \mathrm{U} / \mathrm{L}$ \\
Monocytes & 3.0 & $2-9 \%$ & Total bilirubin & 5.6 & $0.3-1.2 \mathrm{mg} / \mathrm{dL}$ \\
Platelets & 60 & $150-400 \times 10^{3} / \mathrm{mm}^{3}$ & Total protein & 4.2 & $6-8 \mathrm{~g} / \mathrm{dL}$ \\
CRP & 27 & $<5$ & Albumin & 1.6 & $3-5 \mathrm{~g} / \mathrm{dL}$ \\
\hline
\end{tabular}

ALP = alkaline phosphatase; $A L T$ = alanine aminotransferase; $A S T$ = aspartate aminotransferase; $C R P=C$-reactive protein; $\gamma \mathrm{GT}=$ gamma-glutamyl transferase; $\mathrm{RV}=$ reference value.

glutamyl transferase plus a slight elevation of the transaminases. A rectosigmoidoscopy was performed, and rectal biopsies ruled out a cytomegalovirus infection. An immunoassay for the Clostridium difficile infection was negative. The risk of intestinal perforation was considered and the patient was referred to the surgery department for possible colectomy. However, due to the severe clinical status impairment, colectomy could not be undertaken and the patient died of septic shock.

\section{AUTOPSY FINDINGS}

The postmortem examination showed a malnourished patient weighing about $40 \mathrm{~kg}$, measuring $157 \mathrm{~cm}$, with two necrotizing cutaneous lesions: one in the right scapular region measuring $2 \mathrm{~cm}$, and the other close to the right areolar region measuring $0.5 \mathrm{~cm}$.

At the opening of the abdominal and thoracic cavities, there was $3.000 \mathrm{~mL}$ of serosanguineous ascites and serous pleural effusion with $300 \mathrm{~mL}$ in each hemithorax. Gross examination of the gastrointestinal tract revealed involvement of the entire colon by extensive shallow ulcers and pseudopolyps (Figure 2), along with intestinal perforations in the right colon and acute suppurative peritonitis. Histologically, there was severe inflammation in all segments of the colon with effacement of the mucosal architecture. Mucosal inflammation and crypt atrophy were also found in 


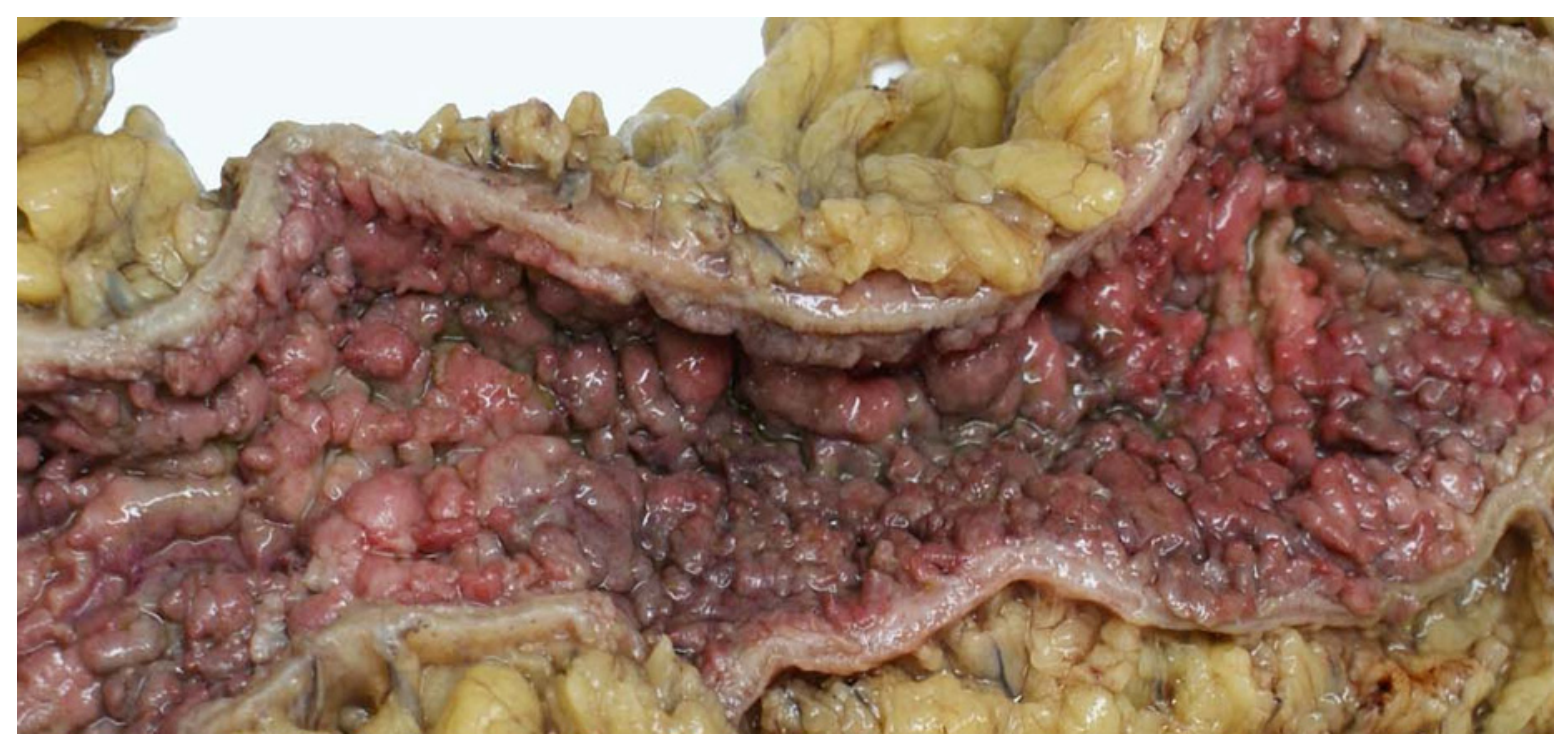

Figure 2 - Gross features of UC: erythematous mucosa with a cobblestone appearance due to shallow ulcers interspersed with pseudopolyps.
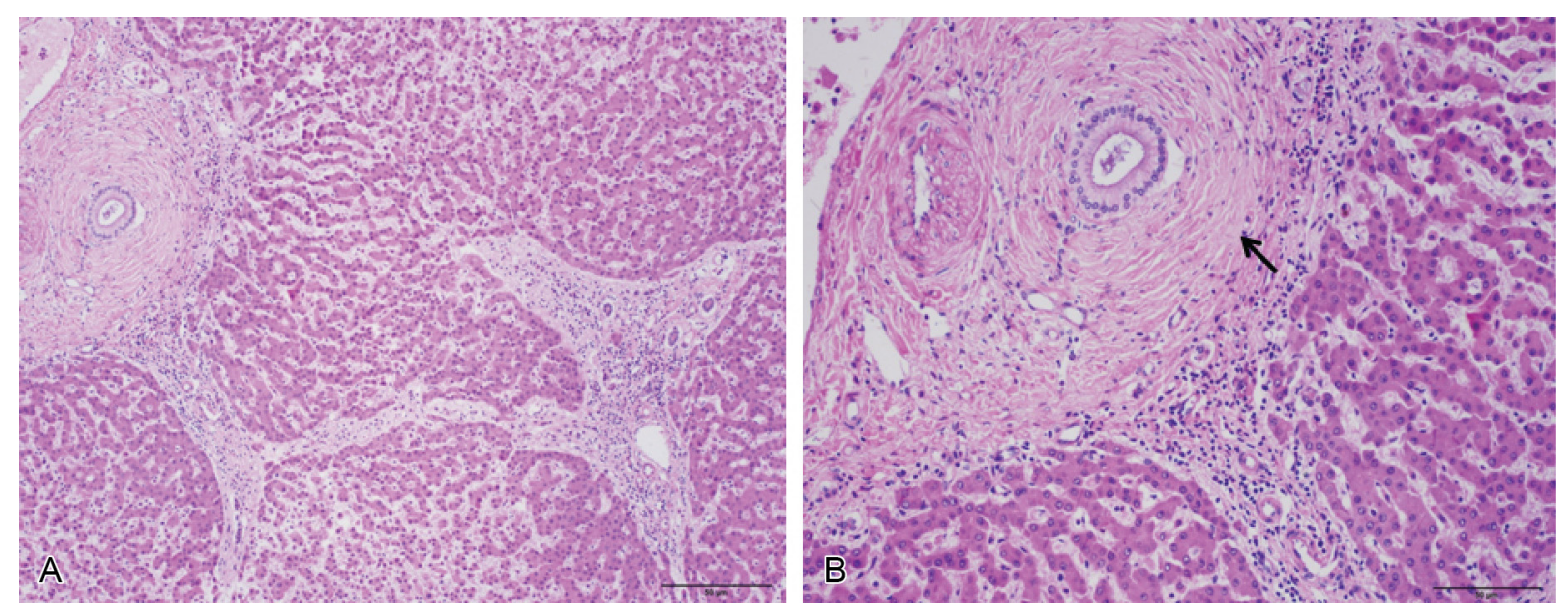

Figure 3 - Photomicrography of the liver. A - Widened portal area with bridging fibrosis and inflammation (HE, 100X); B - Concentric periductal fibrosis (arrow) and chronic inflammation in a portal area (HE, 200X).

the rectum (Figure 1B). The distal ileum presented backwash inflammation. The liver weighed 1550 g (reference value, RV: 1400-1600 g), was macroscopically green colored, with a poorly defined nodular appearance at the cut surface. The histopathological examination revealed chronic inflammation surrounding the bile ducts together with concentric periductal fibrosis and bridging portal fibrosis characterizing primary sclerosing cholangitis (PSC) (Figure 3). Bile ducts were lacking in some portal tracts, but the extrahepatic main biliary tree was preserved.

The spleen was enlarged and soft, weighing $220 \mathrm{~g}$ (RV: $150 \mathrm{~g}$ ). The kidneys were also enlarged and weighed $205 \mathrm{~g}$ and $190 \mathrm{~g}$, the right and left, respectively (RV: 115-155 g). Histologically there was acute nonspecific splenitis and acute tubular necrosis in the kidneys, respectively.

\section{DISCUSSION}

In the present case, the autopsy findings confirmed the clinical diagnosis of severe UC and disclosed the presence of PSC, the most serious hepatobiliary complication of UC. Extraintestinal complications are common in patients with UC. Minor hepatobiliary abnormalities can occur in up to $50 \%$ of patients, but clinically significant liver disease has been detected in less than $10 \%$ of patients. ${ }^{1}$ The clinical association between UC and PSC was described by Smith and Loe (1965). ${ }^{2}$ The prevalence of PSC in patients with UC varies between $2.4 \%$ and $7.4 \%,{ }^{3,4}$ but UC has been found 
in up to $80 \%$ of patients with PSC. ${ }^{5,6}$ The activity of UC does not correlate with the severity of PSC and vice versa. ${ }^{7}$

The diagnosis of primary sclerosing cholangitis used to be a challenging task in pauci or asymptomatic patients. ${ }^{8}$ However, when fatigue, pruritus, and jaundice are present, suspicions should be raised. Laboratory tests usually show elevated determinations of alkaline phosphatase, gammaglutamyltransferase as well as total bilirubins. ${ }^{8,9}$ The diagnosis of primary sclerosing cholangitis is usually confirmed after the development of a complication, like infectious cholangitis. In the present case, the diagnosis of primary sclerosing cholangitis was made only during the postmortem examination by the histological findings of onion skin fibrosis around the bile ducts, along with chronic inflammation surrounding bile ducts. Although laboratory tests showed a typical cholestatic profile, the diagnosis of PSC was not initially considered due to the critical clinical status of the patient.

Although the mechanism of the association of PSC and UC is still not explained, shared inflammatory pathways or a common agent may be involved in the pathogenesis of both diseases. ${ }^{10}$ The hypothesis of autoimmune-mediated mechanisms for PSC has been supported by the presence of various autoantibodies, including perinuclear antineutrophil cytoplasmic antibodies or anti-nuclear antibodies in the serum of PSC patients. ${ }^{11}$ However, the presence of these markers does not help to define PSC due to their lack of specificity.

Some studies have suggested that UC present in PSC patients represents a distinct clinical and pathologic entity. ${ }^{12-14}$ However, a recent investigation of the pathologic characteristics and distribution of colonic disease in patients with primary sclerosing cholangitis reported that UC patients with PSC had similar pathologic findings in the colon compared with UC patients without PSC. ${ }^{15}$

An increased frequency of rectal sparing has been reported in UC patients with $\mathrm{PSC} ;{ }^{12,16}$ however, this finding was not observed in our patient. Joo et al. (2009), ${ }^{15}$ in a matched case control study, showed that the diagnostic procedure of identifying UC in patients with PSC was performed at a significantly earlier age compared with UC patients without PSC, as observed in the present case.
The finding of pancolitis, in our patient, is in agreement with previous studies that showed UC of the entire colon in patients with PSC, based on clinical and endoscopic data. ${ }^{12,16}$ In contrast to recent reports that have observed less severe disease activity in UC patients with PSC, ${ }^{12-14,16}$ our patient presented a severe and fulminant form of UC with backwash ileitis. Severe and uncontrollable symptoms may occur in up to $30 \%$ patients with UC (especially in those who are quite young when diagnosed) thus requiring a colectomy, which effectively cures the intestinal disease. ${ }^{17,18}$ In our patient, a colectomy could not be performed due to the severe clinical status impairment.

Mortality in UC remains debated. Older studies reported a reduced survival in patients with UC,,$^{19}$ whereas recent studies show that the risk of dying in patients with UC does not differ from that of the general population..$^{20,21}$ A meta-analysis of mortality in UC, derived from population-based cohorts, revealed that the overall mortality is not increased among patients with UC. However, a subgroup of patients with newly diagnosed and extensive disease, like our patient, is at a greater risk of dying from the disease and from surgical complications. ${ }^{21}$

\section{CONCLUSION}

The case described herein emphasizes how challenging the clinical diagnosis of primary sclerosing cholangitis can be, especially when associated with a severe form of UC. It highlights the value of postmortem examinations to add important information to medical diagnoses.

\section{REFERENCES}

1. Bernstein CN, Blanchard JF, Rawsthorne P, Yu N. The prevalence of extraintestinal diseases in inflammatory bowel disease: a populationbased study. Am J Gastroenterol. 2001;96:1116-22. PMid:11316157. http://dx.doi.org/10.1111/ j.1572-0241.2001.03756.x

2. Smith M, Loe S. Sclerosing cholangitis: review of recent case reports and associated diseases and four new cases. Am J Surg. 1965;110:239-46. http://dx.doi.org/10.1016/00029610(65)90018-8

3. Aadland E, Schrumpf E, Fausa O, et al. Primary sclerosing cholangitis: a long-term follow-up study. Scand J Gastroenterol.1987;22:655-64. PMid:3659828. http:// dx.doi.org/10.3109/00365528709011139 
4. 4.Shepherd HA, Shelby WS, Chapman RWG, et al. Ulcerative colitis with persistent liver dysfunction. Quart J Med. 1983;52:503-13. PMid:6657913.

5. Broomé $U$, Bergquist A. Primary sclerosing cholangitis, inflammatory bowel disease, and colon cancer. Semin Liver Dis. 2006;26:31-40. PMid:16496231. http://dx.doi. org/10.1055/s-2006-933561

6. Takikawa $\mathrm{H}$, Manabe $\mathrm{T}$. Primary sclerosing cholangitis in Japan - analysis of 192 cases. J Gastroenterol. 1997;32:1347. http://dx.doi.org/10.1007/BF01213311

7. Fausa O, Schrumpf E, Elgjo K. Relationship of inflammatory bowel disease and primary sclerosing cholangitis. Semin Liver Dis. 1991;11:31-9. PMid:2047887. http://dx.doi. org/10.1055/s-2008-1040420

8. Angulo P, Lindor KD. Primary sclerosing cholangitis. Hepatology.1999;30:325-32. PMid:10385674. http://dx.doi. org/10.1002/hep.510300101

9. Schrumpf E, Boberg KM. Primary sclerosing cholangitis: challenges of a new millenium. Dig Liver Dis. 2000;32:753-5. http://dx.doi.org/10.1016/S1590-8658(00)80350-3

10. Pollheimer MJ, Halilbasic E, Fickert P, Trauner M. Pathogenesis of primary sclerosing cholangitis. Best Pract Res Clin Gastroenterol. 2011;25:727-39. PMid:22117638 PMCid:PMC3236286. http://dx.doi.org/10.1016/j. bpg.2011.10.009

11. Angulo P, Peter JB, Gershwin ME, et al. Serum autoantibodies in patients with primary sclerosing cholangitis. J Hepatol. 2000;32:182-7. http://dx.doi.org/10.1016/S0168$8278(00) 80061-6$

12. Loftus EV, Harewood GC, Loftus CG, et al. PSC-IBD: a unique form of inflammatory bowel disease associated with primary sclerosing cholangitis. Gut. 2005;54:916. PMid:15591511 PMCid:PMC1774346. http://dx.doi. org/10.1136/gut.2004.046615

13. Lundqvist K, Broomé U. Differences in colonic disease activity in patients with ulcerative colitis with and without primary sclerosing cholangitis: a case control study. Dis
Colon Rectum. 1997;40:451-6. PMid:9106695. http://dx.doi. org/10.1007/BF02258391

14. Moayyeri A, Daryani N, Bahrami H. Clinical course of ulcerative colitis in patients with and without primary sclerosing cholangitis. J Gastroenterol Hepatol. 2005;20:36670. PMid:15740478. http://dx.doi.org/10.1111/j.14401746.2005.03727.x

15. Joo M, Abreu-e-Lima P, Farraye F, et al. Pathologic features of ulcerative colitis in patients with primary sclerosing cholangitis: a case-control study. Am J Surg Pathol. 2009;33:854-62. PMid:19295408. http://dx.doi.org/10.1097/ PAS.0b013e318196d018

16. Faubion WA Jr, Loftus EV, Sandborn WJ, Freese DK, Perrault J. Pediatric "PSC-IBD": a descriptive report of associated inflammatory bowel disease among pediatric patients with PSC. J Pediatr Gastroenterol Nutr. 2001;33:296-300. http:// dx.doi.org/10.1097/00005176-200109000-00013

17. Farmer RG, Easley KA, Rankin GB. Clinical patterns, natural history, and progression of ulcerative colitis. A long-term follow-up of 1116 patients. Dig Dis Sci.1993;38:1137-46. PMid:8508710. http://dx.doi.org/10.1007/BF01295733

18. Sands BE. Inflammatory bowel disease: past, present and future. J Gastroenterol. 2007;42:16-25. PMid:17322989 PMCid:PMC2780674. http://dx.doi.org/10.1007/s00535006-1995-7

19. Gyde S, Prior P, Dew MJ, Saunders V, Waterhouse JA, Allan RN. Mortality in ulcerative colitis. Gastroenterology. 1982;83:36-43. PMid:7075944.

20. Jess T, Loftus Jr EV, Harmsen WS, et al. Survival and cause specific mortality in patients with inflammatory bowel disease: A long-term outcome study in Olmsted County, Minnesota, 1940-2004. Gut. 2006;55:12485. PMid:16423890 PMCid:PMC1860022. http://dx.doi. org/10.1136/gut.2005.079350

21. Jess T, Gamborg M, Munkholm P, Sørensen TI. Overall and cause-specific mortality in ulcerative colitis: metaanalysis of population-based inception cohort studies. Am J Gastroenterol. 2007;102:609-17. PMid:17156150. http:// dx.doi.org/10.1111/j.1572-0241.2006.01000.x

\section{Conflict of interest: None}

Submitted on: $13^{\text {th }}$ September 2013

Accept on: $3^{\text {rd }}$ December 2013

Correspondence: Departamento de Patologia

Faculdade de Medicina da Universidade Estadual Paulista

Av. Rua Bento Lopes, s/n - Distrito de Rubião Jr. - Botucatu/SP - Brazil

CEP: 18618970 - Phone: +55 (11) 3811-6238

E-mail: mariar@fmb.unesp.br 
